\title{
PERTUMBUHAN DAN KELULUSAN HIDUP KEPITING BAKAU (Scylla serrata, Forskal) DENGAN PERLAKUAN SALINITAS BERBEDA
}

\author{
(Growth and Survival rate of Mud Crab (Scylla serrata, Forskal) on \\ Different Medium Salinity)
}

\section{Erly kaligis}

Program Studi Ilmu Kelautan, Fakultas Perikanan dan IImu Kelautan, Universitas Sam Ratulangi, Manado

e-mail : erly_kaligis@yahoo.co.id

The purpose of this experiment was to find out the optimum salinity decrease for growth and survival rate of mud crab, Scylla serrata. The seed weighing from 47.65 to 51.32 gram and carapace length $64,35-71.30 \mathrm{~mm}$. They were placed into 12 tanks $(1 \mathrm{~m} \times 1 \mathrm{~m} \times 0.4 \mathrm{am})$ with density of four crabs. The mud crab was fed with freshly chicken intestines, about $10 \%$ of weight per day. Water was exchanged more than $150 \%$ per week. In the first time of experiment. each tank have same salinity (33 ppt). Every week, each tank was applied with decreasing of salinity according to treatment: constan salinity (A), decreasing salinity of $2 \mathrm{ppt}$ (B). decreasing salinity of $4 \mathrm{ppt}(\mathrm{C})$ and decreasing salinity of $6 \mathrm{ppt}(\mathrm{D})$. The result of the experiment showed that decreasing salinity of $4 \mathrm{ppt}$ was the best for the growth of mud crab, but no effect to crab's survival.

Key words : Salinity, Growth, Survival rate, Mud Crab

Tujuan dari penelitian ini adalah untuk mendapatkan penurunan salinitas optimal bagi pertumbuhan dan kelulusan hidup kepiting bakau, Scylla serrata. Bobot benih yang digunakan sekitar 47,65-51,32 gram dan panjang karapas 64,35-71,30 mm dan dimasukkan dalam 12 tangki $(1 \mathrm{~m} \times 1 \mathrm{~m} \times 0,4 \mathrm{~m})$ dengan kepadatan 4 ekor. Kepiting diberi makan usus ayam segar sekitar $10 \%$ bobot perhari. Penggantian air lebih dari $150 \%$ per minggu. Pada awal percobaan setiap tangki berisi salinitas yang sama (33 ppt). Setiap minggu tiap tangki dilakukan penurunan salinitas sesuai perlakuan, yaitu (A) salinitas tetap, (B) penurunan salinitas $2 \mathrm{ppt}$, (C) penurunan salinitas $4 \mathrm{ppt}$, dan (D) penurunan salinitas 6 ppt. Hasil penelitian menunjukkan bahwa penurunan salinitas 4 ppt adalah perlakuan terbaik untuk kepiting bakau, tetapi tidak berpengaruh pada nilai kelulusan hidup.

Kata kunci : Salinitas, Pertumbuhan, Kelulusan hidup, Kepiting bakau

\section{PENDAHULUAN}

Kepiting bakau (Scylla serrata) merupakan salah satu jenis krustasea yang mempunyai nilai ekonomis tinggi dan hidup di perairan pantai khususnya hutan bakau (mangrove) (Kanna, 2002). Kepiting bakau lebih suka hidup di perairan yang relatif dangkal, dengan dasar berlumpur. Menurut FAO (2011), kriteria lahan yang cocok sebagai lokasi budidaya yaitu tambak berlumpur dengan suhu $25-35{ }^{\circ} \mathrm{C}$; $\mathrm{pH}$ 7,0-9,0; $\mathrm{DO}>5 \mathrm{ppm}$; dan kadar garam berkisar 10-30 ppt.

\begin{abstract}
Perkembangan budidaya kepiting bakau hingga saat ini belum sepesat budidaya udang windu (Penaeus monodon) atau udang vaname (Litopenaeus vannamei). Salah satu kendala yang belum terpecahkan dalam pemeliharaan kepiting bakau diantaranya adalah perubahan salinitas air tambak. Perubahan salinitas akan berpengaruh pada fisiologi dan morfologi organisme melalui proses osmoregulasi atau perimbangan cairan dan koefisien penyerapan cairan pada tubuh organisme, sedangkan pada
\end{abstract}


lingkungan menyebabkan perubahan kejenuhan gas-gas terlarut, densitas dan viskositas (Kinne, 1963). Perubahan salinitas yang berkepanjangan apalagi jika berada di luar batas toleransi akan menghambat pertumbuhan bahkan menyebabkan kematian karena energi yang berasal dari pakan habis dalam mengatur konsentrasi cairan tubuh.

Rodriguez et al. (2007) menyatakan bahwa batas toleransi salinitas untuk kepiting bakau cukup besar yaitu 15-35 ppt. Menurut Davenport and Wong (1987); Tangkrock-Olan and Ketpadung (2009), $S$. serrata tergolong hiperosmoregulator pada salinitas di bawah salinitas air laut bahkan memiliki kemampuan hidup yang tinggi hingga salinitas kurang dari 5 ppt. Informasi tentang penurunan salinitas diperlukan karena akan memberikan dampak pertumbuhan yang maksimum pada kepiting bakau berkaitan dengan proses osmoregulasinya, dan penerapan selanjutnya di lingkungan tambak. Penelitian ini bertujuan mendapatkan penurunan salinitas optimal bagi pertumbuhan dan kelulusan hidup kepiting bakau, $S$. serrata. Diharapkan dari hasil penelitian ini dapat menjadi bahan informasi untuk pengembangan budidaya kepiting bakau.

\section{METODE PENELITIAN}

Hewan uji kepiting bakau yang digunakan memiliki kisaran berat awal 47,65 - 51,32 gram dan lebar karapas 64,35 - 71,30 mm. Pemeliharaan menggunakan wadah berupa bak berukuran $1 \mathrm{~m} \times 1 \mathrm{~m} \times 0,5 \mathrm{~m}$. Bagian sisi dalam bak dilapisi plastik dan diisi pasir setebal $5 \mathrm{~cm}$ sebagai substrat serta ketinggian air $10 \mathrm{~cm}$. Setiap bak dilengkapi dengan aerasi dan rumpunan tali rafia sebagai pelindung. Hewan uji kemudian dimasukkan dalam bak dengan kepadatan 4 ekor per bak.

Pemberian pakan dan pengaturan salinitas rutin dilaksanakan. Pakan yang digunakan adalah usus ayam segar sebanyak $10 \%$ dari berat badan per hari dengan frekuensi pemberian dua kali sehari. Pada awal penelitian salinitas tiap bak sama (33 ppt). Tiap minggu masing-masing unit bak dilakukan penurunan salinitas yang berbeda sesuai perlakuan (kecuali kontrol). Pengenceran dilakukan dengan penambahan air tawar.

Penelitian ini menggunakan rancangan acak lengkap dengan empat perlakuan dan tiga ulangan, yaitu: perlakuan A (salinitas tetap $33 \mathrm{ppt}$ /kontrol), perlakuan B (salinitas diturunkan 2 ppt per minggu). perlakuan $\mathrm{C}$ (salinitas diturunkan $4 \mathrm{ppt}$ per minggu), dan perlakuan $D$ (salinitas diturunkan 6 ppt per minggu).

Peubah yang diukur setiap minggu adalah pertumbuhan berat dan lebar karapas sedang kelulusan hidup pada akhir penelitian. Rumusan dari peubah yang digunakan dalam penelitian sebagai berikut.

1. Pertumbuhan berat mutlak (Ricker, 1975 dalam Effendie, 1979).

$$
\mathrm{h}=\mathrm{Wt}-\mathrm{Wo}_{\mathrm{o}}
$$

dimana :

$\mathrm{h}=$ Pertumbuhan berat mutlak individu rata-rata (gr)

$\mathrm{Wt}=$ Berat tubuh individu rata-rata pada waktu t (gr)

Wo $=$ Berat awal individu rata-rata (gr)

2. Lebar karapas mutlak individu ratarata (Ricker, 1975 dalam Effendie, 1979).

$$
\begin{aligned}
\mathrm{I}= & \mathrm{Lt}-\mathrm{Lo} \\
\text { dimana }: & \\
\mathrm{I}= & \text { Pertumbuhan lebar karapas } \\
& \text { mutlak individu rata-rata } \\
& (\mathrm{mm}) \\
\mathrm{Lt}= & \text { Lebar karapaks individu rata- } \\
& \text { rata pada waktu }(\mathrm{mm}) \\
\mathrm{Lo}= & \text { Lebar karapaks awal } \\
& \text { ndividu rata-rata }(\mathrm{mm})
\end{aligned}
$$

3. Penentuan pertumbuhan berat badan harian maupun lebar karapas harian individu rata-rata dihitung 
berdasarkan metode dari Jauncey and Ross (1982).

In Wt - In Wo

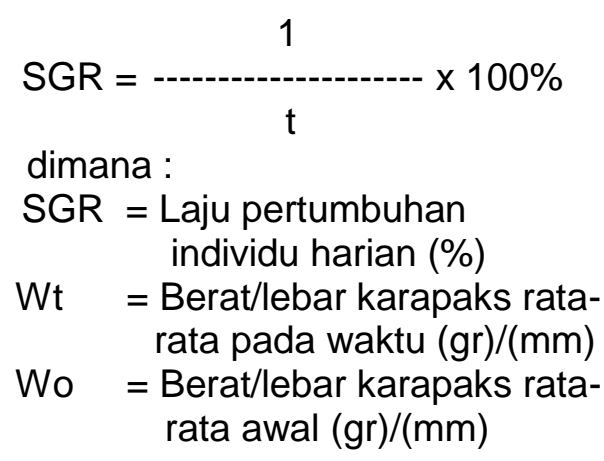

4. Tingkat kelulusan hidup (Ricker, 1975 dalam Effendie, 1979)

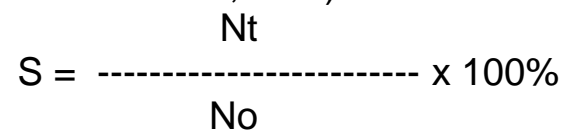

dimana :

$\mathrm{S}=$ Tingkat kelulusan hidup (\%)

$\mathrm{Nt}=$ Populasi Akhir (ekor)

No $=$ Populasi awal (ekor)

Untuk mengetahui pengaruh perlakuan terhadap pertumbuhan berat mutlak, berat harian, lebar karapas mutlak, lebar karapas harian dan kelulusan hidup, digunakan analisis sidik ragam. Bila ada perbedaan maka dilakukan analisis lanjutan dengan uji Beda Nyata Terkecil (BNT) menurut petunjuk Sujana (1985).

\section{HASIL DAN PEMBAHASAN}

Data pertumbuhan berat mutlak dan berat harian individu rata-rata kepiting bakau selama 6 minggu dapat dilihat pada Tabel 1. Hasil penelitian yang diperoleh lewat pengukuran berat mutlak dan berat harian individu menunjukkan adanya pertambahan berat setiap minggu. Analisis sidik ragam terhadap pertumbuhan mutlak dan pertumbuhan harian menunjukkan adanya pengaruh perlakuan. Hasil uji BNT memperlihatkan bahwa perlakuan $A$ (kontrol), B (penurunan $2 \mathrm{ppt)}$ dan $\mathrm{C}$ (penurunan 4 ppt) memberi pengaruh yang sama terhadap laju pertumbuhan berat mutlak, namun pada perlakuan $D$ (penurunan 4 ppt) didapatkan laju pertumbuhan yang berbeda. Uji BNT terhadap pertumbuhan berat harian menunjukkan perlakuan A dan B tidak berbeda dengan perlakuan $\mathrm{C}$, tetapi perlakuan $B$ dan $C$ berbeda dengan perlakuan $D$.

Pengaruh masing-masing perlakuan menunjukkan bahwa perlakuan dengan penurunan salinitas 6 ppt didapatkan laju pertumbuhan mutlak dan pertumbuhan harian terendah. Hal ini disebabkan oleh laju penurunan salinitas yang besar yaitu dari 33 ppt pada awal penelitian hingga salinitas 3 ppt selama 6 minggu. Perubahan kondisi salinitas ini menyebabkan sifat fungsional terganggu (Kinne, 1964), sehingga proses osmoregulasi untuk menyeimbangkan cairan tubuh dengan lingkungan akan berlangsung terus.

Warner (1977) menyatakan bahwa untuk dapat menyesuaikan diri dengan salinitas lingkungan yang berubah-rubah, kepiting akan merubah konsentrasi cairan tubuhnya sesuai dengan lingkungannya melalui proses osmosis dan difusi. Menurut

Tabel 1. Pertumbuhan berat mutlak dan berat harian kepiting bakau selama 6 minggu.

\begin{tabular}{|c|c|c|}
\hline Perlakuan & $\begin{array}{c}\text { Pertumbuhan mutlak } \\
\text { (gram) }\end{array}$ & $\begin{array}{c}\text { Pertumbuhan harian } \\
(\%)\end{array}$ \\
\hline A & 9,6950 & 0,5107 \\
B & 10,2067 & 0,5247 \\
C & 11,6800 & 0,6041 \\
D & 7,6100 & 0,4110 \\
\hline
\end{tabular}


Tabel 2. Pertumbuhan lebar karapas mutlak dan lebar karapas harian kepiting bakau selama 6 minggu.

\begin{tabular}{|c|c|c|}
\hline Perlakuan & $\begin{array}{c}\text { Pertumbuhan lebar } \\
\text { mutlak }(\mathrm{mm})\end{array}$ & $\begin{array}{c}\text { Pertumbuhan lebar } \\
\text { harian }(\%)\end{array}$ \\
\hline A & 5,9300 & 0,2210 \\
B & 6,2900 & 0,2316 \\
C & 7,2400 & 0,2644 \\
D & 4,4933 & 0,1684 \\
\hline
\end{tabular}

Davenport and Wong (1987), tipe hiperosmoregulator termasuk kepiting bakau memiliki kemampuan untuk bertahan hidup karena mampu mengatur konsentrasi osmotik tubuh seimbang dengan lingkungan. Lockwood (1967) menyatakan bahwa ketika terjadi perubahan salinitas maka konsentrasi ion pada sel akan terganggu sehingga akan menyerap air secara osmosis dari darah. Dalam pengaturan ini, ion akan dibuang melalui urine serta melalui difusi pada permukaan tubuh. Apabila hal ini terus berlanjut maka energi bagi pertumbuhan akan habis hanya untuk proses tersebut.

Perlakuan A, B, dan C menunjukkan bahwa salinitas pada seluruh perlakuan ini cukup mendukung pertumbuhan kepiting. Kepiting membutuhkan salinitas optimal seiring dengan bertambahnya umur kepiting, dan hal sesuai pendapat Kinne (1964), bahwa kisaran total salinitas akan berbeda menurut umur dan tingkatan hidup. Penurunan salinitas hingga $4 \mathrm{ppt}$ ternyata mampu mendukung pertumbuhan kepiting. Pada kondisi salinitas yang baik ini terjadi penyimpanan energi untuk pertumbuhan.

Laju pertumbuhan lebar karapas dan lebar karapas harian individu kepiting bakau selama 6 minggu dapat dilihat di Tabel 2. Pertumbuhan lebar karapas mutlak dan lebar karapas harian, menunjukkan kecenderungan bertambah. Analisis sidik ragam menunjukkan adanya pengaruh perlakuan. Uji BNT pertumbuhan mutlak menunjukkan perlakuan kontrol (A) dan penurunan salinitas 2 ppt (B) tidak berbeda dengan perlakuan penurunan salinitas 4 ppt (C), namun perlakuan $A, B$ dan $C$ berbeda dengan perlakuan penurunan salinitas 6 ppt (D) sedangkan uji BNT pertumbuhan harian individu menujukkan perlakuan $A$ tidak berbeda dengan perlakuan $B, C$ dan $D$ tetapi perlakuan $\mathrm{B}$ dan $\mathrm{C}$ berbeda dengan D.

Pertumbuhan lebar mutlak karapas maupun pertumbuhan lebar harian terendah yang ditunjukkan pada perlakuan $D$ (penurunan salinitas $6 \mathrm{ppt}$ ) karena kondisi yang tidak sesuai sehingga proses pertumbuhan karapas menjadi melambat. Menurut Warner (1977), faktor lingkungan internal maupun eksternal mempengaruhi proses ganti kulit (molting), dan rendahnya frekuensi molting mengakibatkan penambahan lebar karapas kecil, padahal setiap kali molting juvenil kepiting bisa mengalami penambahan lebar karapas sekitar 2144,8 \% (Dittel and Epifanio, 1984).

Perlakuan A, B, dan C memberikan pengaruh yang sama terhadap laju pertumbuhan karapas dan lebar karapas Hal ini mendukung hasil pertumbuhan bobot yang didapatkan tinggi pada perlakuanperlakuan salinitas demikian. Kisaran perubahan salinitas hingga 4 ppt diduga lebih mirip dengan habitat kepiting bakau di alam ketika terjadi fluktuasi salinitas.

Tingkat kelulusan hidup kepiting bakau selama penelitian berkisar antara 76,24 - 88,62 \%. Hasil analisis 
sidik ragam menunjukkan bahwa laju penurunan salinitas tidak berpengaruh pada kelulusan hidup kepiting bakau, artinya penurunan salinitas hingga 6 ppt per minggu selama 6 minggu pemeliharaan tidak menurunkan kelulusan hidup kepiting bakau. Hasil ini menggambarkan bahwa kepiting bakau termasuk organisme euryhalin dengan toleransi salinitas sangat lebar dan penurunan hingga $6 \mathrm{ppt}$ per minggu masih ditolerir dengan kelulusan hidup yang tinggi. Davenport and Wong (1987); Tangkrock-Olan and Ketpadung (2009) melaporkan bahwa salinitas di atas salinitas air laut, $S$. serrata tidak mampu beradaptasi dengan baik, namun mampu beradaptasi (hiperosmoregulator) pada salinitas 5-35 ppt.

\section{KESIMPULAN}

Dari hasil penelitian dapat ditarik kesimpulan sebagai berikut.

1. Laju penurunan salinitas hingga 4 ppt per minggu dapat memberi pertumbuhan optimal pada kepiting bakau baik terhadap berat badan maupun lebar karapas.

2. Laju penurunan salinitas tidak memberi pengaruh pada tingkat kelulusan hidup kepiting bakau.

\section{DAFTAR PUSTAKA}

Davenport, J., Wong, T.M. 1987. Reponses of adult mud crabs (Scylla serrata) (Forskal) to salinity and low oxygen tension. Comparative Biochemistry and Physiology 86A: 43-47.

Dittel. A.I.,. Epifanio, C.E. 1984. Growth and Development Portunited Crab Callinectes arcuatus Ordwav: Zoea, Megalope and Juvenile. Journal of Crustacea Biology, 4(3):491 - 494.

Elfendie.M. 1979. Biologi Perikanan. Bagian I. Natural Hisitori. Fakultas Perikanan IPB. Bogor.
(FAO] Food and Agriculture Organization. 2011. The State of Word Fisheries and Aquaculture. Rome: FAO.

Jauncey, K., Ross, B.1992. A Guide to Tilapia Feeds and Feeding. Institul of Aquaculture University of Stirling Scotland.

Kanna, I, 2002. Budidaya Kepiting Bakau. Penerbit Kanisius. ISBN 979-67698-148.Jakarta. Hal 512.

Kinne, O. 1964. The Effects of Marine Temperature and Salinity' on Marine and Brackishvvater Animals. In. Salinity and Temperature Combinations. Oceanography and Marine Biology Annual Review, 2:281339.

Krishnamoorthy, R.V., Venkatramiah, A. 1969. Myosin ATPase Activity in an Estuarine Decapod Crustacean. Scylla serrataas Function of Salionity Ad aptation. Mar.Bio.. 4 : 345 - 348.

Lockwood. A.P.M., 1967. Aspects of the Physiology' of Caisatace. Freeman and Co. San Francisco.

Rodriguez E.M, Parado-Estepa F.D, Quinitio E.T. 2007. Extension of nursery culture of Scylla serrata (Forsskål) juveniles in net cages and ponds. Aquaculture Research 38: 1.588-1.592.

Sujana. 1985. Disain dan Analisis Eksperimen. Tarsito, Banidung.

Tangkrock-Olan, N., Ketpadung, R. 2009. A Comparative Study on the Blood Osmolality of the Mud Crab (Scylla serrata) and the Blue Swimming Crab (Portunus pelagicus) Exposed to Different 
Salinities: A Case Study for the Topic "Osmotic Regulation" in High School Biology. Asian Journal of Biology Education 4:8-14.

Warner, G.F. 1977. The Biology of Crab. Elek Science. London 